often a member of the College Council, such as the Chief Examiner or the Dean. Trainees themselves have addressed their colleagues on issues such as part-time training and training in peripheral hospitals.

Trainees' days serve a useful educational and social function. The published reports of trainees' days almost uniformly refer to them as "successful" despite variable attendance of trainees. The poor attendance of senior registrars and clinical tutors (which is more regrettable) has been noted more than once. However, the participation of senior representatives of the College is particularly welcome.

Annual talks on traditional topics, such as the MRCPsych examinations, are likely to be repetitive and the recent tendency to experiment with more varied programmes is of interest: non-psychiatrists are invited to speak and computer demonstrations have been introduced. Yet there is more opportunity for innovation: formal debates, for example, have not featured in any of the present series. In addition, the time is overdue for a systematic ascertainment of the 'consumers' wishes for trainees' day.

\section{Acknowledgements}

We wish to thank Dr Max Harper, U. Duffy and P.P. P. Duffy for helpful comments on the manuscript, Mrs Jean Wales for copies of the trainees' day programmes and the Mental Health Foundation for financial support.

\section{References}

GADHV, H., MARTIN, R. \& Sharma, R. (1983) Chiltern and Thames Valley Division Trainees' Day. Bulletin of the Royal College of Psychiatrists, 7, 37.

Jones, D., RigBY, J. \& SMITH, J. (1989) South Western Division trainees' day. Psychiatric Bulletin, 13, 151-152. LOVETT, J. W. T. (1987) Welsh Division trainees' day. Bulletin of the Royal College of Psychiatrists, 11, 32-33.

RICE, P. \& MEDLEY, I. (1987) Report on the Scottish Trainees' Day. Bulletin of the Royal College of Psychiatrists, 11, 392-394.

\title{
Higher training in old age psychiatry
}

\section{JCHPT (Joint Committee in Higher Psychiatric Training) Position Statement:}

The JCHPT has reviewed the training of senior registrars in old age psychiatry and wishes to draw the following points to the attention of scheme organisers, trainers, trainees, and others interested in the topic.

Many senior registrars training in general psychiatry will appropriately receive a one year training in old age psychiatry as part of their four year programme. The following points refer to senior registrars seeking to become specialists in old age psychiatry.

(1) A full higher training for someone seeking to work whole-time or almost whole-time in old age psychiatry should include two years in old age psychiatry and two years in general psychiatry.

(2) The two psychogeriatric years should include experience with two different psychogeriatric teams and trainers. As far as possible these should be complementary or contrasting experiences, and as main or 'core' placements should generally occupy six to eight sessions weekly.
(3) The programme should also provide relevant experiences other than with specialist psychogeriatric services. These should include: attachment to a department of geriatric medicine; liaison with neuroradiology, neurophysiology, and neurology departments; psychological treatments including family methods relevant to the old age field; and liaison with primary care settings. Some of these may appropriately be taken in 'special interest' sessions during general psychiatry years of training.

(4) Each scheme should have a trainer responsible, within the scheme organisation, for old age psychiatry in the scheme.

(5) Whenever possible, an old age psychiatrist should participate in senior registrar appointment committees whose task is to appoint trainees who may have the opportunity to become a specialist old age psychiatrist.

September 1989 